\section{An epidemiological survey of extended-spectrum $\beta$-lacta- mases producing bacteria genotypes and the evaluation of the antimicrobial effect of Rhazya stricta leaf extract}

\author{
Saleh Abdullah Ali Kabli, ${ }^{1}$ \\ Alaa EI Din Abdelbasit Hadhoud, ${ }^{2}$ \\ Mohammed Nabih Baeshen' \\ ${ }^{1}$ Department of Biological Sciences, \\ Faculty of Science, King Abdulaziz \\ University, Jeddah, Saudi Arabia; \\ ${ }^{2}$ Medical Microbiology Department, \\ National Liver institute, Al-Menophya \\ University, Egypt
}

\section{Abstract}

An epidemiological survey and evaluation of the anti-bacterial growth effect of the aqueous leaf extract of the traditional medicinal plant Rhazya stricta were undertaken for extended-spectrum $\beta$-lactamase's producing bacteria isolates collected from the King Abdulaziz Hospital and Oncology Center. Results showed high rates of extended-spectrum $\beta$-lactamase (ESBL) isolates (49.2\%) compared to non-ESBL isolates (50.8\%). The surgical intensive care unit was the hospital site showing the highest rate (15.1\%) of infection, followed by the women's medical ward (11.2\%). Urine samples were the highest source of infection (40\%). Prevalence among Saudis was $66.67 \%$ as compared to non-Saudis (33.33\%). Prevalence according to gender was $51.94 \%$ females and $48.06 \%$ males. Age groups 51-60 years, 21-30 years, and 61 years and over showed the highest rates $(20.93 \%, 20.54 \%$ and $20.16 \%$, respectively) compared with other age groups. $E$. coli resistance rates were $94.5 \%$ for ceftazidime, $98.18 \%$ for cefotaxime, $92.73 \%$ for cefepime and $93.75 \%$ for aztreonam. On the other hand, in cases of $K$. pneumoniae resistance, rates were $100 \%$ for ceftazidime, $100 \%$ for cefotaxime, $98.68 \%$ for cefepime and $97.29 \%$ for aztreonam. Genetic analysis showed 8 genotypes, 4 of them were for $E$. coli and 4 for $K$. pneumoniae. Analysis also showed genetic diversities between the ESBL and the non-ESBL types in their genomic DNA. There was no antimicrobial effect of the plant extract against all study isolates, although the antimicrobial growth had an effect upon some of the control strains.

\section{Introduction}

Many natural and synthetic antibiotics are available today, but many pathogenic microbes lose their ability to resist them and many strains became multi drug resistant (MDR). ${ }^{1,2}$ However, with the development of new generation antibiotics, new resistant strains are emerging. Since all microbial properties are controlled by genetic factors, new acquired resistance within a strain may emerge by transferring genetic properties from another strain or by genetic mutations in the same strain. ${ }^{3-5}$ The new genetic properties will change the response of a microorganism to a particular antibiotic, and change the mechanism of action against this antibiotic by adding new physiological characteristics. These could include the alteration of the cell membrane permeability which reduces the efficiency of antibiotic diffusion through the microbial cell, changes in antibiotic targets, or the formation of metabolic compounds that can deactivate the antibiotic. ${ }^{2,5,6}$ Notably, a microbe can acquire resistance to an antibiotic without showing any morphological changes because the resistant gene might be inert and may be activated in its offspring. Therefore, the continued antibiotic resistance for the microbe may result from the continuous genetic changes. These microbial mutations are due to exposure from continuous environmental factors that can modulate the resistant genes..$^{2,3,5}$

One group of MDR organisms is made up of extended spectrum $\beta$-lactamases (ESBLs). These produce bacteria and include members of the Enterobacteriaceae family that resists many beta-lactams antibiotics, and some other classes of antibiotics. For this reason, they are considered MDRs. ESBLs include strains from $E$. coli, $K$. pneumoniae and $K$. oxytoca. Recently, Proteus mirabilis has been added to the group and considered an ESBL producing bacteria.-9 ESBLs have natural resistance to some beta-lactams as members of the Enterobacteriaceae family. They acquired new resistant properties by mutations to new types, and classes of antibiotics by self-mutation under the pressure of the overuse of antibiotics, or by accepting new genetic properties from other strains from the same species or even other species. ${ }^{10,11}$ The ESBL phenomenon is a new emerging problem that threatens hospitals and other health care centers all over the world.6,8,12,13 Recently, new cases have been reported as community-acquired ESBL infections. ${ }^{11,12,14}$ The infections caused by ESBL are serious and may lead to death because therapeutic options are limited. ${ }^{12}$ New studies are being considered on strains of ESBLs resistant to
Correspondence: Mohammed Nabih Baeshen, Department of Biological Sciences, Faculty of Science, King Abdulaziz University, Jeddah, Saudi Arabia.

E-mail: mnbaeshen@kau.edu.sa

Key words: extended spectrum $\beta$-lactamases, Rhazya stricta.

Acknowledgments: the authors would like to thank Dr. Fariborz J. Abadi, Prof. Nabih A. Baeshen, Dr. Sufian El-Assouli, Mr. Zaki ElAssouli, Dr. Salah Eldeen Abo Aba, Prof. Fotouh M. El-Domyati, Prof. Mohamed M M. Ahmed and Prof. Ahmed Bahieldin for their support and advice. The authors would also like to thank King Abdulaziz University and in particular the Department of Biological Sciences - Faculty of Science, King Fahd Research Center and King Abdulaziz University Hospital. Our thanks also go to the Ministry of Health represented by King Abdulaziz Hospital and Oncology Center and also to medical supplies administration.

Conflict of interests: the authors report no potential conflict of interests.

Received for publication: 25 August 2011. Revision received: 8 February 2012.

Accepted for publication: 16 February 2012

This work is licensed under a Creative Commons Attribution NonCommercial 3.0 License (CC BYNC 3.0).

@C Copyright S.A.A. Kabli Kabli et al., 2012 Licensee PAGEPress, Italy

Microbiology Research 2012; 3:e16

doi:10.4081/mr.2012.e16

all $3^{\text {rd }}$ generation cephalosporins, cefepime $^{12,15-19}$ and, more recently, carbapenems. ${ }^{12,20}$ Some ESBL strains became MDR organisms by acquiring resistance against non $\beta$-lactam antibiotics, such as quinolones and colistin. ${ }^{4,21}$

The search for alternative therapeutic solutions to treat the infections and diseases caused by resistant strains, such as medicinal plants, may solve the problem of antibiotic withdrawal. Medicinal plants can be used along with antibiotics in certain cases or alone in others. This may reduce and rationalize the use of antibiotics. Medicinal plants have been used for generations to treat infections and diseases. ${ }^{22-24}$ Many medicinal plants that grow naturally in the Kingdom of Saudi Arabia were used in traditional medicine to treat microbial infections and diseases. ${ }^{25,26}$ Therefore, research and studies on these local plants must be carried out to learn more about their therapeutic benefits and side effects, and to allow their use to be standardized. Notably, producing drugs from such 
plants will cost much less than producing and manufacturing a new antimicrobial agent. $^{22,23,27}$

Rhazya stricta is a local shrub that grows naturally as normal flora. $R$. stricta has long been recognized as a medicinal plant in many countries for a whole range of infections caused by microorganisms. 1,27,28 Later studies and research proved the antimicrobial effect of $R$. stricta against many species and strains of microorganisms. ${ }^{29-33} R$. stricta is a plant rich in chemical compounds and secondary metabolites, but the therapeutic activities of most of these compounds have still not been discovered. ${ }^{31}$ The genotypic methods give a clear vision for the genetic content of a microbe, whether that genetic material be inert, active, borne, or acquired. This creates a DNA fingerprint or map which cannot be diagnosed by phenotypic methods. This allows us to control the outbreaks of a certain microbial disease in a particular area by knowing the route of transmission and the source of microbe from its DNA fingerprint, and then comparing it with the data base of all known DNA fingerprints. Such phenomenon can, therefore, be much more easily controlled. ${ }^{34,35}$ On the other hand, the classical methods of detecting pathogenic microorganisms are limited when compared to molecular and genetic methods which give highly accurate and specific results. ${ }^{36}$

Many techniques are used to detect and describe bacterial strains, such as plasmid fingerprinting (PF), restriction endonuclease analysis (REA), restriction fragment length polymorphism (RFLP) typing, pulse field gel electrophoresis (PFGE) and polymerase chain reaction (PCR) assay. ${ }^{34,35,37,38}$ Gel electrophoresis for chromosomal DNA analysis can be used to study all kinds of living organisms, and can be used to distinguish between strains. ${ }^{21}$ It is considered the gold standard because of its high differentiation ability. ${ }^{35}$ The use of gel electrophoresis for the digested chromosomal DNA by restriction enzymes is useful to compare and distinguish between the different isolates and strains from the same species..$^{39,40}$ According to the ESBL outbreaks, and the ability of $R$. stricta to inhibit the growth of microorganisms, this study will focus on: i) statistical and epidemiological aspects of the ESBL phenomenon; ii) the genetic properties of ESBLs producing bacteria in order to classify the genotypes; iii) the antimicrobial activity of the aqueous extract of the $R$. stricta leaf with the same dose and preparation used in traditional medicine against ESBLs producing bacteria.

\section{Materials and Methods}

\section{Bacterial strains}

Two hundred and fifty-eight bacterial isolates were collected from the medical microbiology laboratory of the King Abdulaziz Hospital and Oncology Center at Jeddah, Saudi Arabia: 128 E. coli isolates (55 ESBL, 73 non-ESBL), $128 \mathrm{~K}$. pneumoniae isolates (56 ESBL, 72 non-ESBL), and 2 non-ESBL K. oxytoca isolates. Data for isolates were recorded for statistical analysis, and then stored in glycerol at $-20^{\circ} \mathrm{C}$ as recommended in the Clinical and Laboratory Standards Institute/National Committee for Clinical Laboratory Standards (CLSI/NCCLS). The effect of the plant extract was then tested on 69 isolates (18 non-ESBL $E$. coli, 17 ESBL $E$. coli, 11 non-ESBL $K$. pneumoniae, and 19 ESBL $K$. pneumoniae), and 34 isolates (13 non-ESBL $E$. coli, 11 ESBL $E$. coli, 5 non-ESBL $K$. pneumoniae, and 5 ESBL $K$. pneumoniae) were used for molecular analysis and genotyping. All isolated samples were cultured and identified from the King Abdulaziz Hospital and Oncology Center Manual following CLSI/NCCLS protocols. Samples were cultured on blood, chocolate and MacConkey agar except for urine samples which been cultured on CLID agar. All cultures were cultivated at $37^{\circ} \mathrm{C}$ for $18 \mathrm{~h}$, and then identified and diagnosed by microbial chemical tests. Antibiotic sensitivity tests were performed using Phoenix (USA) and Microscan (Siemens, USA) instrumentation to identify the ESBL and non-ESBL isolates. Samples were later exposed for the disk diffusion test (as a confirmatory test for ESBL isolates), then subcultured on MacConkey agar for further study.

\section{Control bacterial strains}

Two control strains (E. coli ATCC 35218 and $K$. pneumoniae ATCC 13883 ) were provided by Medical Supply Stores, Jeddah (Ministry of Health), one control strain (ESBL K. pneumoniae ATCC 700603) was provided by the King Abdulaziz University Hospital, Jeddah, and one control strain (ESBL $E$. coli ATCC 25922) was provided by the King Faisal Specialist Hospital and Research Centre, Jeddah. Other control strains (Proteus mirabilis ATCC 14153, Pseudomonas aeruginosa ATCC 27853, Staphylococcus epidermidis ATCC 12228 and Staphylococcus aureus ATCC 25923) were provided by Medical Supply Stores.

\section{Plant materials}

Plant materials were collected from different parts of Jeddah, on the Makkah road, at

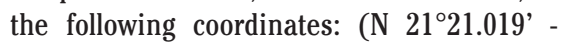
E039 $\left.32.830^{\prime}\right)$, (N 21 ${ }^{\circ} 21.033^{\prime}$ - E039 $32.871^{\prime}$ ),
(N 21 $23.318^{\prime}$ - E039²5.894'), (N 21 ${ }^{\circ} 21.019^{\prime}$ -

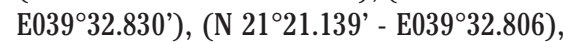
(N 21 ${ }^{\circ} 21.164$ ' - E039 $\left.34.121^{\prime}\right)$, (N 21 ${ }^{\circ} 21.062^{\prime}$ E039 $\left.32.833^{\prime}\right),\left(\mathrm{N} 21^{\circ} 22.460^{\prime}-\mathrm{E} 039^{\circ} 31.157^{\prime}\right)$, (N 21 $\left.{ }^{\circ} 22.612^{\prime}-\mathrm{E} 039^{\circ} 30.967^{\prime}\right),\left(\mathrm{N} 21^{\circ} 22.707^{\prime}\right.$ $\left.\mathrm{E} 039^{\circ} 27.871^{\prime}\right),\left(\mathrm{N} 21^{\circ} 23.740^{\prime}-\mathrm{E} 039^{\circ} 24.622^{\prime}\right)$, (N 2124'429 - E039²31'268').

The plant stems were collected in plastic bags labeled with the following details: the scientific name of the plant, date of collection, coordinates of the area, researcher's name and height of the plant. Plants were placed in an ice box for further studies. Later the plant was identified and classified at the Herbarium of Biological Sciences Department, Faculty of Sciences, King Abdulaziz University, Jeddah.

\section{Preparation of plant extract}

Leaves were separated from stems and washed with distilled water, and were then cut manually by hand into small pieces. One liter of distilled water was mixed in a blender with $96 \mathrm{~g}$ of leaves, and the mixture was left for $24 \mathrm{~h}$ in a shaker at room temperature. The mixture was later filtered with filter paper $(125 \mathrm{~mm})$, and then with a membrane filter $(0.22 \mu \mathrm{m})$. The stock solution with a concentration of $96 \mathrm{~g} / \mathrm{L}$ can be stored for one week in a refrigerator. Experimental doses can be prepared from the stock solution by diluting in distilled water. The traditional dose is $6 \mathrm{~g} / \mathrm{L}$ and 3 doses were prepared: $3 \mathrm{~g} / \mathrm{L}, 6 \mathrm{~g} / \mathrm{L}$ and 12 $\mathrm{g} / \mathrm{L}$ (the experimental dose, half dose and double dose).

\section{Genotypic fingerprinting}

Thirty-four isolates (13 non-ESBL $E$. coli, 11 ESBL $E$. coli, 5 non-ESBL $K$. pneumoniae, and 5 ESBL $K$. pneumoniae) plus the control stains were activated for genotyping and molecular analysis as described in Drabber. ${ }^{41}$

\section{DNA extraction}

Experimental isolates and control strains were cultured on MacConkey agar, and incubated for $24 \mathrm{~h}$ at $37^{\circ} \mathrm{C}$. The next day, two colonies from each MacConkey agar plate were cultured in $10 \mathrm{~mL}$ test tubes containing Trypton Soy Broth, and incubated for $24 \mathrm{~h}$ at $37^{\circ} \mathrm{C}$. The third day, the test tubes which contain the bacterial colonies were placed in a centrifuge at $5000 \mathrm{rpm}$ for $10 \mathrm{~min}$. Supernative liquid was carefully discharged and DNA was extracted manually from bacterial precipitate pellets according to Drabber. ${ }^{41}$

\section{Measuring DNA concentration}

Bacterial DNA, RNA and proteins were measured by Spectrophotometer (GeneQuant 1300, GE Healthcare Life Sciences, USA), and DNA concentration was determined for all readings as: reading at $260 \mathrm{~nm} \bullet 50 \bullet 100 / 1000$ 
Table 1. Prevalence of study strains and the ratio of extended-spectrum $\beta$-lactamases to non-extended-spectrum $\beta$-lactamases isolates.

\begin{tabular}{|c|c|c|c|c|c|c|c|c|c|c|c|c|c|c|}
\hline & \multicolumn{4}{|c|}{$E$ coli } & \multicolumn{4}{|c|}{ K. pneumoniae } & \multicolumn{4}{|c|}{ K. oxytoca } & \multicolumn{2}{|c|}{ Total } \\
\hline & \multicolumn{2}{|c|}{$\begin{array}{l}\text { ESBL } \\
\text { isolates }\end{array}$} & \multicolumn{2}{|c|}{$\begin{array}{c}\text { Non-ESBL } \\
\text { isolates }\end{array}$} & \multicolumn{2}{|c|}{$\begin{array}{c}\text { ESBL } \\
\text { isolates }\end{array}$} & \multicolumn{2}{|c|}{$\begin{array}{l}\text { Non-ESBL } \\
\text { isolates }\end{array}$} & \multicolumn{2}{|c|}{$\begin{array}{c}\text { ESBL } \\
\text { isolates }\end{array}$} & \multicolumn{2}{|c|}{$\begin{array}{l}\text { Non-ESBL } \\
\text { isolates }\end{array}$} & $\begin{array}{l}\text { ESBL } \\
\text { isolates }\end{array}$ & \multirow{2}{*}{$\begin{array}{l}\text { Non-ESBL } \\
\text { isolates } \\
\text { No. \% }\end{array}$} \\
\hline & No. & $\%$ & No. & $\%$ & No. & $\%$ & No. & $\%$ & No. & $\%$ & No. & $\%$ & No. $\%$ & \\
\hline & 55 & 21.3 & 73 & 28.3 & 72 & 27.9 & 56 & 21.7 & 0 & 0 & 2 & 0.8 & $127 \quad 49.2$ & $131 \quad 50.8$ \\
\hline \multirow[t]{2}{*}{ Total } & & No. & $\%$ & & & No. & $\%$ & & & No. & $\%$ & & & \\
\hline & & 128 & 49.6 & & & 128 & 49.6 & & & 2 & 0.8 & & 258 & 100 \\
\hline
\end{tabular}

ESBL, extended-spectrum -lactamases

\section{Gel electrophoresis}

Detection of genomic and plasmid DNA

Agarose gel electrophoresis $(0.8 \%)$ was performed for all 40 samples (ESBL and nonESBL isolates from all strains and species) for $2 \mathrm{~h}$ at 100 volts.

\section{DNA digestion}

DNA for all samples was digested by Hind III restriction enzyme according to Drabber. ${ }^{41}$ Then, the samples were run on $0.7 \%$ Agarose gel. The gel electrophoresis process was carried out for $1 \mathrm{~h}$ and $45 \mathrm{~min}$ at 120 volts.

The effect of Rhazya stricta aqueous leaf extract on bacterial strains

\section{Experimental tests and methodology}

The tests performed included disk diffusion, wells, micro and macrodilutions.

All suspensions for bacterial strains and isolates were prepared directly before every experiment by concentrations of 0.5 McFarland for agar tests, and 1 McFarland for broth tests.

\section{Pilot experiment}

The effect of the aqueous extract was first tested by the Kirby-Bauer disk diffusion method according to CLSI/NCCLS protocols on four control strains: 1-Gram negative control strain Proteus mirabilis ATCC 14153 and Pseudomonas aeruginosa ATCC 27853; 2-Gram positive control strains Staphylococcus epidermidis ATCC 12228 and Staphylococcus aureus ATCC 25923.

\section{Diffusion experiments}

Kirby-Bauer disk and wells diffusion tests were applied for 69 isolates (18 non-ESBL $E$. coli, 17 ESBL $E$. coli, 11 non-ESBL $K$. pneumoniae, and 19 ESBL $K$. pneumoniae), and 4 reference strains ( $E$. coli ATCC 35218, ESBL $E$. coli ATCC 25922, K. pneumoniae ATCC 13883 and 19 ESBL $K$. pneumoniae ATCC 700603) as control group according to CLSI/NCCLS proto-

Table 2. Prevalence of non-extended-spectrum $\beta$-lactamases and extended-spectrum $\beta$ lactamases isolates of $K$. pneumonia and $E$. coli.

\begin{tabular}{cccc} 
ESBL & Rneumoniale & E coli \\
isolates & $\begin{array}{c}\text { Non-ESBL } \\
\text { isolates } \\
\%\end{array}$ & $\begin{array}{c}\text { ESBL } \\
\text { isolates }\end{array}$ & $\begin{array}{c}\text { Non-ESBL } \\
\text { isolates } \\
\%\end{array}$ \\
56.25 & 43.75 & 42.97 & 57.03 \\
\hline
\end{tabular}

cols. The effect of the three concentrations of the plant extract $(3 \mathrm{~g} / \mathrm{L}, 6 \mathrm{~g} / \mathrm{L}$, and $12 \mathrm{~g} / \mathrm{L})$ on each agar plate was examined against the bacterial strains and isolates.

\section{Serial dilutions experiments}

Microdilution and microdilution tests were applied according to CLSI/NCCLS protocols on all study samples. Muller Hinton broth was used for these experiments.

\section{Results}

\section{Prevalence of the study}

Statistical analyses were performed according to data collected and recorded from case reports of the medical microbiology laboratory at the King Abdulaziz Hospital and Oncology Center, Jeddah. Results of 258 cases were analyzed: 55 ESBL $E$. coli, 73 non-ESBL $E$. coli, 56 ESBL $K$. pneumoniae, 72 non-ESBL $K$. pneumoniae, 2 non-ESBL $K$. oxytoca, and no ESBL $K$. oxytoca isolates were recorded.

\section{Strains and isolate prevalence}

An equal number of $E$. coli and $K$. pneumoniae isolates were recorded compared to $\mathrm{K}$. oxytoca isolates which is very unusual; only 2 non-ESBL isolates were recorded, while there were no ESBL.

In general, there were $49.2 \%$ ESBL for all study isolates compared to non-ESBL isolates
(50.8\%). These results are very similar indicating the high level of the ESBL phenomena (Tables 1 and 2).

Rates of sites of infection on hospital medical wards and in hospital units

The percentages of ESBL isolates emulated those of non-ESBL in the different departments of the hospital, and were even higher in some other cases (Table 3 ). The highest rates among the hospital departments as sources of infection were the surgical intensive care unit (15.1\%), the women's medical ward (11.2\%), the men's medical ward (9.7\%), the outpatient clinics (8.9\%), the men's surgical ward (8.1\%), the neonatal intensive care (8.1\%), and female surgical ward (7.4\%), while the lowest rate was $0.4 \%$ at the Burn Unit.

\section{Sources of infection}

Urine samples recorded the highest percentage $(40.39 \%)$ as a source of infection for all the isolates of $E$. coli and $K$. pneumoniae, followed by sputum samples (18.22\%). The urine samples that contained ESBL $E$. coli isolates had the highest rates among all samples (Table 4).

\section{Infected patient according to nationalities}

In general, rates of infected Saudis (66.67\%) were higher than non-Saudis (33.33\%); this was also true for both ESBL and non-ESBL 
Table 3. Ratios of extended-spectrum $\beta$-lactamases and non-extended-spectrum $\beta$-lactamases isolates according to medical wards and units.

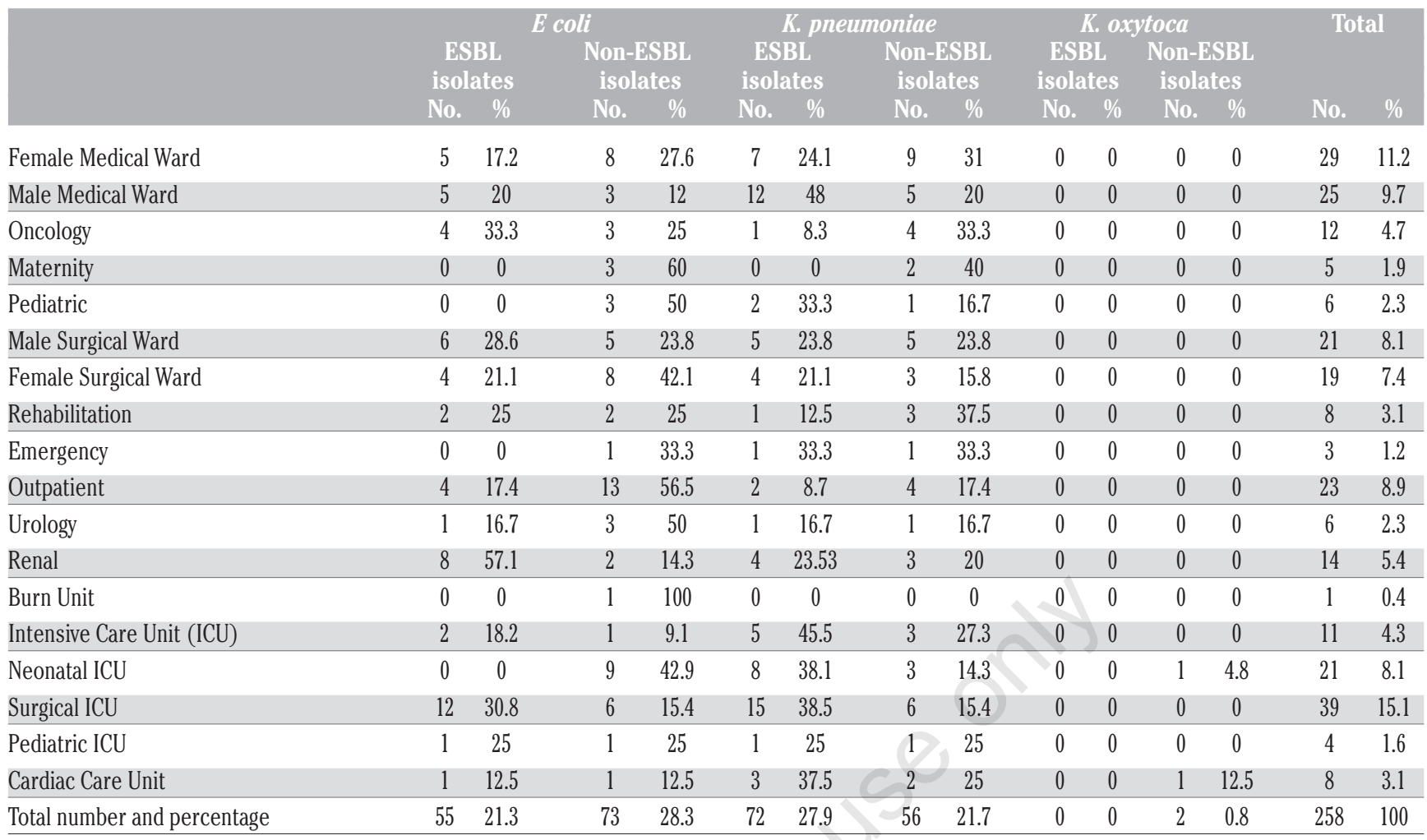

ESBL, extended-spectrum $\beta$-lactamases; ICU, Intensive Care Unit

Table 4. Ratios of extended-spectrum $\beta$-lactamases and non-extended-spectrum $\beta$-lactamases isolates according to sources of infection.

\begin{tabular}{|c|c|c|c|c|c|c|c|c|c|c|c|c|c|c|}
\hline & \multicolumn{4}{|c|}{ E coli } & \multicolumn{4}{|c|}{ K. pneumoniae } & \multicolumn{4}{|c|}{ K. oxytoca } & \multicolumn{2}{|c|}{ Total } \\
\hline & \multicolumn{2}{|c|}{$\begin{array}{l}\text { ESBL } \\
\text { isolates }\end{array}$} & \multicolumn{2}{|c|}{$\begin{array}{c}\text { Non-ESBL } \\
\text { isolates }\end{array}$} & \multirow{2}{*}{\multicolumn{2}{|c|}{$\begin{array}{l}\text { ESBL } \\
\text { isolates }\end{array}$}} & \multicolumn{2}{|c|}{$\begin{array}{l}\text { Non-ESBL } \\
\text { isolates }\end{array}$} & \multicolumn{2}{|c|}{$\begin{array}{c}\text { ESBL } \\
\text { isolates }\end{array}$} & \multicolumn{2}{|c|}{$\begin{array}{l}\text { Non-ESBL } \\
\text { isolates }\end{array}$} & \multirow[b]{2}{*}{ No. } & \multirow[b]{2}{*}{$\%$} \\
\hline & No. & $\%$ & No. & $\%$ & & & No. & $\%$ & No. & $\%$ & No. & $\%$ & & \\
\hline Urine & 28 & 26.9 & 40 & 38.5 & 20 & 19.2 & 16 & 15.4 & 0 & 0 & 0 & 0 & 104 & 40.31 \\
\hline Throat & 1 & 14.3 & 2 & 28.6 & 1 & 14.3 & 3 & 42.9 & 0 & 0 & 0 & 0 & 7 & 2.71 \\
\hline Stool & 0 & 0 & 0 & 0 & 6 & 1 & 100 & 0 & 0 & 0 & 0 & 0 & 1 & 0.39 \\
\hline Vagina & 4 & 28.6 & 6 & 42.9 & 0 & 0 & 4 & 28.6 & 0 & 0 & 0 & 0 & 14 & 5.43 \\
\hline Umbilical cord & 0 & 0 & 2 & 50 & 0 & 0 & 2 & 50 & 0 & 0 & 0 & 0 & 4 & 1.55 \\
\hline Pus & 1 & 25 & 2 & 50 & 0 & 0 & 1 & 25 & 0 & 0 & 0 & 0 & 4 & 1.55 \\
\hline Groin & 0 & 0 & 3 & 100 & 0 & 0 & 0 & 0 & 0 & 0 & 0 & 0 & 3 & 1.16 \\
\hline Axilla & 0 & 0 & 1 & 50 & 0 & 0 & 1 & 50 & 0 & 0 & 0 & 0 & 2 & 0.78 \\
\hline Peritoneal & 2 & 25 & 6 & 75 & 0 & 0 & 0 & 0 & 0 & 0 & 0 & 0 & 8 & 3.10 \\
\hline Perianal & 0 & 0 & 1 & 100 & 0 & 0 & 0 & 0 & 0 & 0 & 0 & 0 & 1 & 0.39 \\
\hline Blood & 6 & 26.1 & 2 & 8.70 & 10 & 43.5 & 5 & 21.7 & 0 & 0 & 0 & 0 & 23 & 8.91 \\
\hline Abdominal & 0 & 0 & 1 & 100 & 0 & 0 & 0 & 0 & 0 & 0 & 0 & 0 & 1 & 0.39 \\
\hline Sputum & 4 & 8.5 & 2 & 4.26 & 25 & 53 & 15 & 31.9 & 0 & 0 & 1 & 2.13 & 47 & 18.22 \\
\hline Urethra & 0 & 0 & 0 & 0 & 0 & 0 & 1 & 100 & 0 & 0 & 0 & 0 & 1 & 0.39 \\
\hline Tracheal & 0 & 0 & 0 & 0 & 5 & 62 & 3 & 37 & 0 & 0 & 0 & 0 & 8 & 3.10 \\
\hline Lungs & 0 & 0 & 1 & 100 & 0 & 0 & 0 & 0 & 0 & 0 & 0 & 0 & 1 & 0.39 \\
\hline Hip & 1 & 50 & 0 & 0 & 1 & 50 & 0 & 0 & 0 & 0 & 0 & 0 & 2 & 0.78 \\
\hline Wounds & 8 & 40 & 4 & 20 & 6 & 30 & 2 & 100 & 0 & 0 & 0 & 0 & 20 & 7.75 \\
\hline Stomach & 0 & 0 & 0 & 0 & 1 & 100 & 0 & 0 & 0 & 0 & 0 & 0 & 1 & 0.39 \\
\hline Nose & 0 & 0 & 0 & 0 & 1 & 50 & 0 & 0 & 0 & 0 & 1 & 50 & 2 & 0.78 \\
\hline Deep wounds & 0 & 0 & 0 & 0 & 0 & 0 & 2 & 100 & 0 & 0 & 0 & 0 & 2 & 0.78 \\
\hline Ileum & 0 & 0 & 0 & 0 & 1 & 100 & 0 & 0 & 0 & 0 & 0 & 0 & 1 & 0.39 \\
\hline Spinal fluid & 0 & 0 & 1 & 100 & 0 & 0 & 0 & 0 & 0 & 0 & 0 & 0 & 1 & 0.39 \\
\hline Total numbers and ratios & 55 & 21.3 & 73 & 28.3 & 72 & 27.9 & 56 & 21.7 & 0 & 0 & 2 & 0.8 & 258 & 100 \\
\hline
\end{tabular}


infections. The numbers of Saudis infected by ESBL was higher than the number of nonSaudi patients (Supplementary Table 1).

\section{Infected patients according to gender}

Generally, there were more infections in females (51.94\%) than in males (48.06). Percentages were higher in males infected by ESBL isolates (28.29\%) than females infected by ESBL isolates (20.93\%) (Supplementary Table 2).

\section{Infected patients according to age}

The highest percentage of infection (20.93\%) was recorded for those patients aged between 51 and 60 years, followed by the 60 year old age group (20.16\%), and that between 21 to 30 years $(20.02 \%)$. Some age groups recorded a higher rate of infection from ESBL isolates than the non-ESBL isolates (Supplementary Table 3).

\section{Comparison of multiple to single infections}

The samples which refer to single ESBL infections recorded a rate of $68.5 \%$ of all samples compared to those containing more than one bacterial strain in addition to the study strains (31.5\%). The study detected samples containing ESBL strains together with other hospital-acquired nosocomial pathogens.

Response rates of extended-spectrum $\beta$-lactamase's producing strains to $\beta$-lactams antibiotics

Scientists described ESBLs producing bacteria as strains that acquired resistance to $3^{\text {rd }}$ generation cephalosporins (ceftazidime, cefotaxime and cefepime) and aztreonam as a monobactam.

All study groups of ESBL strains were tested against the concentration of antibiotics described in Supplementary Table 4. All ESBL strains were resistant to $3^{\text {rd }}$ generation cephalosporins and aztreonam by high rates that reached $100 \%$ in some cases (Supplementary Table 5). All isolates were sensitive to certain carbapenems (meropenem and impenem). ESBL isolates were resistant to other antibiotics rather than cephalosporins and monobactams. We also recorded high rates of resistance to other $\beta$-lactams and other classes of antibiotics that for some reached 100\% (Supplementary Table 6). This resistance to certain antibiotics might be intrinsic or acquired. The multi-resistant phenomena to different classes, groups and generations of antibiotics led scientists to describe ESBL producing bacteria as multi-drug-resistant (MDR) organisms. Supplementary Table 7 shows the rates of resistance in non-ESBL isolates to antibiotics. High rates of resistance to ampecillin reaching $100 \%$ were recorded; this

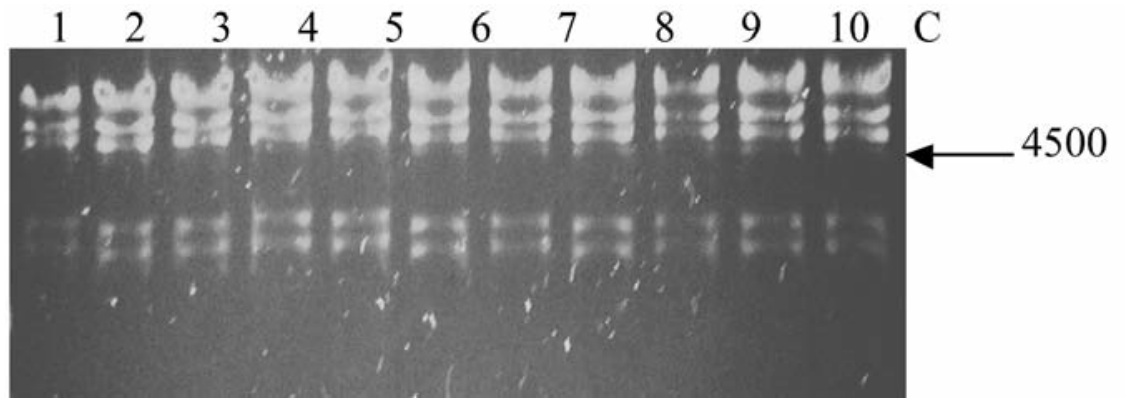

Figure 1. Restriction endonuclease analysis of $K$. pneumoniae isolates after digestion with HindIII. Lanes 1-5 = non- extended-spectrum $\beta$-lactamases isolates, lanes 6-10 = extended-spectrum $\beta$-lactamases isolates, C = ATCC 13881 .

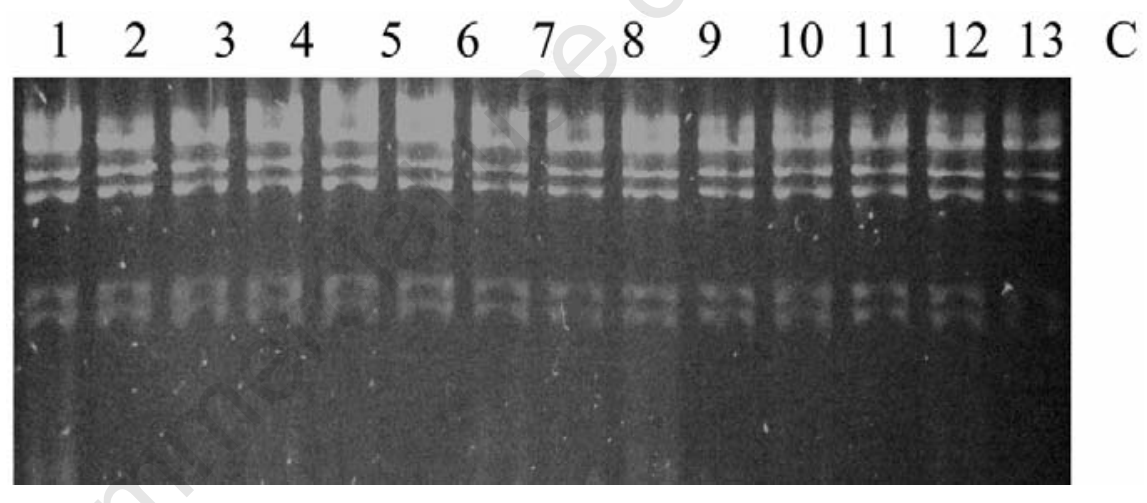

Figure 2. Restriction endonuclease analysis of non- extended-spectrum $\beta$-lactamases $E$. coli isolates (1-13) after digestion with HindIII. Lane C = ATCC 13881 .

Figure 3. Restriction endonuclease analysis of extended-spectrum $\beta$-lactamases $E$. coli isolates (1-11) after digestion with HindIII. Lane C = ATCC 13881. 
is natural because it has intrinsic resistance to such antibiotics. The surprise was in the emergence of new ESBL strains described as non-ESBL by the classical laboratory diagnosis. The rates of resistance for these isolates were very low compared to those originally described as ESBL strains. This might refer to genetic mutations that transferred from ESBL to non-ESBL strains. Therefore, genotyping and molecular analysis for such cases are essential in order to detect and determine these sensitive parameters that may not be identified by classical methods. The resistance rates of emerged ESBL isolates are described in Supplementary Table 7. The molecular analysis of study isolates presents some clearly genetic explanations for this phenomenon.

\section{Genotype fingerprinting}

Fingerprints of genomic and plasmid DNAs of all studied isolates and strains treated with HindIII restriction enzyme are shown in Figures 1, 2 and 3. The results of ESBL and nonESBL $K$. pneumoniae isolates (Figure 1) showed a polymorphic band with a molecular weight of approximately $2500 \mathrm{bp}$ that was present in ESBL isolates but absent in non-ESBL isolates. No differences were observed within each group of isolates indicating the homogeneity within ESBL as well as within nonESBL $K$. pneumoniae isolates. Similar results were observed for the non-ESBL $E$. coli isolates; no differences were observed from DNA fingerprints among different non-ESBL isolates after being digested with HindIII restriction enzyme (Figure 2). On the other hand, the REA analysis of ESBL $E$. coli isolates indicated the occurrence of molecular genetic variations as a number of six polymorphic bands, with a range of 1500-5500 bp, were observed (Figure 3).

\section{Antimicrobial effect of $R$. stricta aqueous leaf extract}

Although the strong antimicrobial effect of the plant extract on both Staphylococcus reference strains (as a gram positive bacteria) was tested by disk diffusion method (Figure 4), the plant extract had no effect on the other two gram positive reference strains (Proteus and Pseudomonas) or any of study isolates (as a gram negative bacteria) which was tested by disk diffusion, wells, macro and microdilution methods at all concentrations of plant extract.

\section{Discussion}

The number of cases recorded in this study indicates high rates of spread of the targeted strains in the hospital environment in 19 wards and units. Some of these wards were sources of high rates of ESBL infection com-

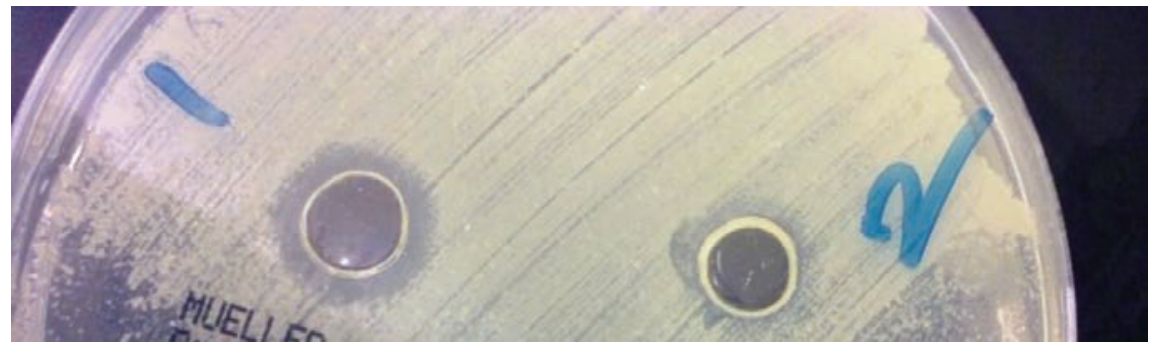

Figure 4. The antimicrobial effect of $R$. stricta leave extract against Staphylococcus spp.; a Gram positive bacterium. Number 1; represents the inhibition zone of a diameter of $13 \mathbf{~ m m}$ for the effect of the concentration of $12 \mathrm{gm} / \mathrm{L}$. Number 2: represents the Inhibition zone of a diameter of $12 \mathrm{~mm}$ for the effect of the concentration of $6 \mathrm{gm} / \mathrm{L}$ (the folkloric dose).

pared to non-ESBLs. The various intensive care units (ICUs) were the main sites of infection. This agrees with literature in confirming that ICUs are the source of all ESBL infections around the world and this reflects the weak immune status of the patients in these units. The present study showed that the highest rates of resistant organisms of ESBL $K$. pneumoniae were found in the men's medical ward (48\%), followed by ICU (45.5\%), surgical ICU (38.5\%), neonatal ICU (38.1\%), then cardiac ICU (37.5\%), ER (33.3\%), and the pediatric ICU (25\%). In contrast, ESBL $E$. coli cases showed the highest rates on the nephrology ward $(57.1 \%)$, followed by oncology (33.3\%), surgical ICU (30.7\%), men's surgical ward (28.6\%), and the pediatric ICU (25\%, similar to rates for $K$. pneumoniae). Interestingly, there was a frequent high rate of occurence for more than one strain on the same ward or unit. When comparing our results with the records of Mehrgan and Ruhbar (2007) in an Iranian hospital, which reported rates of $75.6 \%$ in ICUs, $66.4 \%$ on medical wards and $62 \%$ on surgical wards, it was found that there was a similar high occurence of these resistant pathogens on the same wards and units, but with lower rates. However, this is not reassuring because other reports of high rates were found in the present study. Furthermore, the records were taken from all hospital departments in our study as compared with the Mehrgan and Ruhbar study, which only presents their records from three departments. This should draw our attention to this emerging phenomenon in the Kingdom of Saudi Arabia and stimulate further study and research. It should also attract the attention of infection control departments in hospitals allowing them to take the necessary precautions against such phenomena. Patients in hospital or outpatients may acquire serious untreatable infections while undergoing tests and treatment in the hospital departments. These may then be transmitted around the community at large, as discussed by Paterson, ${ }^{6}$ Melzer and Petersen, ${ }^{12}$ and others who confirm that the prevalence of blood stream infections by ESBL producing bacteria reached $6.6 \%$ of all community acquired infections.

In general, the rates of the samples that contain ESBL producing bacteria was almost equal to those of non-ESBL ( 49.2 and $50.8 \%$, respectively); these are not reassuring figures. Comparing these results with those of the AlJasser study in Riyadh, ${ }^{8}$ which recorded a rate of $64.2 \%$ for the ESBL positive samples collected from blood media, we found that they exceed the results from our study. However, this does not indicate a decrease because a rate of $49.2 \%$ still represents almost half of all samples.

The results of the statistical analysis showed high rates of infection within urine samples, followed by remarkable rates of infection in blood, sputum and wound samples. The low rates for infection in the rest of the samples is actually not reassuring given that resistant strains were still found on almost all wards and in areas where the samples came from. This indicates the spread of resistant nosocomial pathogens throughout the hospital and in outpatient sources indicating the spread of the resistant organisms across the community.

The current study shows even more ESBL isolates and a rising resistance among nonESBL isolates to all types of antibiotics. Because of this, the presence of organisms resistant to many groups of antibiotics across health care centers and communities indicates the possible disastrous consequences of an outbreak of multi-drug resistant organisms,

Health control criteria must be applied inside and outside hospitals by prompting and stimulating infection control and allowing public health centers to take action against the problem of multi-drug resistant organisms by promoting health awareness, health control, and running workshops and training courses for hospital and non-hospital employees. Also, studies and research into the control and prevention of such phenomenon are required to make sure that the resultant feedback and rec- 
ommendations will be applied by the competent authorities.

A notable result is the high rates of infection by ESBLs producing bacteria among Saudis; this may be because there were more Saudi patients in hospital than non-Saudis. The prevalence varied between infected males and females; it was sometimes higher in males and sometimes higher in females. As source of infection, in this study, urine samples recorded the highest rates among all other samples, and this corresponds with the other studies reviewed. ${ }^{12,13}$ The rates of infected persons according to age in our study resembles those reviewed by Mehrgan and Ruhbar, 2008, whereas the highest rates in both studies were for patients aged 60 years or over. The lowest rates in the study were found in the 1-10 year age group.

Rates of resistance to ESBL antibiotics were high in this study, even higher than other studies. Rodriguez-Villalobos et al. ${ }^{15}$ reported high rates of resistance to ceftazidime and cefepime (70 and 45\%, respectively). But these results were lower than those recorded in this study, whereas the rates of resistance to cephalosporins was over $92 \%$, and even reached $100 \%$ in some cases. In spite of the terrifying rates of resistance to cephalosporins, the local strains of ESBL producing bacteria are still sensitive to carbapenems, whereas other studies showed resistance to such antibiotics around the world. ${ }^{10,15,41}$ These results are reassuring because mutations could still occur and resistant genes could transfer between strains even from country to country around the world.

It is interesting that there are high rates for resisting antibiotics for $\beta$-Lactams, i.e. quinolones, and this is something we should worry about. It is also worthy of note that the resistance rates are higher in the non-ESBL isolates, which indicates the occurence of new quinolones-resistant strains. Again, this is a cause for concern. It should be noted that rates are generally higher in $2^{\text {nd }}$ generation rather than $3^{\text {rd }}$ generation quinolones, although we should not underestimate the rates recorded for $3^{\text {rd }}$ generation quinolones such as levofloxacin which appear to be high compared with some rates reported for other antibiotics.

Ogbolu et al. ${ }^{4}$ and Strenger et al. ${ }^{21}$ reported high rates of resistance to $4^{\text {th }}$ generation quinolones and colistin, respectively. On comparing their results with those from our study, we would conclude that avoiding the use of these antibiotics in our hospital does not indicate the absence of resistance, but it does ensure a reduction in the occurrence of new resistant mutations.

Statistical analysis of DNA concentrations did not show any significant results within the $K$. pneumoniae or the $E$. coli isolates, whether for ESBL or non-ESBL strains, compared to control strains. Genotyping by restriction endonuclease analysis (REA) was performed on the DNA of all study isolates as a method of identification, detection and diagnosis. REA results showed some molecular genetic variations between the isolates of every species. These variations also appeared between the ESBL and non-ESBL isolates. The REA technique showed 8 new genotypes from 34 of the study isolates. This reflects the mutations at the level of chromosomal DNA or plasmid DNA as reviewed by Tenover et al. ${ }^{34}$ These results must be followed up in future studies using other molecular techniques, such as PCR, plasmid analysis, DNA sequencing and REA by more than one restriction enzyme. The results of our study showed the successful differentiation between strains and isolates, and this agrees with reports by Healy et al. ${ }^{35}$ stating that the REA technique is the gold standard because it has a high differentiation capacity. Importantly, the present study confirms reports by Tenover et al..$^{34}$ discussing the role of genotyping and how it has become an essential part of the epidemiological studies related to hospital and health care centers in evaluating the genetic variation found among strains. In our study, the use of REA also had the advantage of detecting some genetic molecular markers. This agrees with reports by Yakubu et al. ${ }^{37}$

Our results agree with those of BenHamuoda et al. ${ }^{39}$ allowing us to recommend the use of genotyping methods in the case of an epidemiological emergency in specific hospital or heath care centers on isolates collected from different units and wards to identify genetic variations and design strategies against the resistant pathogens.

The results of both the statistical and the genetic analysis demonstrate the genetic changes across the bacterial generations which transform a sensitive strain to a strain resistant to certain antibiotics. The results of statistical studies showed resistance to aztreonam and cefepime from some of the nonESBL isolates in both species (K. pneumoniae and $E$. coli), two of the four antibiotics that determine the antibiotic susceptibility of ESBL strains. This can be explained by the appearance of plasmids in the digested and the undigested DNA of ESBL isolates that also appeared in some of the isolates identified by the traditional methods of diagnosis as non-ESBL isolates. Further genetic analysis should be carried out as described by Fang et al. ${ }^{40}$ to detect and record the resistant genes. Genotyping and molecular studies of resistant pathogens offer a sensitive diagnosis that most traditional methods cannot, and this helps to trace the problem and specify the appropriate cure or drug treatment.

The negative results of the antimicrobial effect on the study isolates may refer to the natural resistance of these microbes to many drugs and medicines. If we compare our study with that of Ahmed et al. ${ }^{28}$ we find that the plant extract was effective against the same species as in our study; this was because Ahmed et al. used more than one part of the plant and more than one method of extraction. This leads us to recommend further research into the plant against these and other resistant pathogens with more fractions, different doses and more than one part of the plant, and also to test other medicinal plants and natural products against these powerful organisms. After the positive results obtained for the plant extractions against the resistant pathogens, we must study all possible side effects.

\section{Conclusions}

ESBL and other MDR organisms are emerging both on a local and a global level. Taking action against this phenomenon is mandatory. Using natural resources like medicinal plants as an alternative therapeutic solution or to synergize with antibiotics may help control this problem. More studies should be carried out on $R$. stricta and other plants by testing all kinds of plant fractions or the effective isolated secondary metabolites on such resistant pathogens.

Further epidemiological studies applying statistical and molecular analysis should be carried out among these resistant pathogens in more hospitals and areas, both locally and globally, in order to increase awareness of the dimension of such a phenomenon and, therefore, control it. By collecting and analyzing the required data, initiatives can be taken in both hospital and community environments and the different roles involving infection control may be determined. Genotyping and molecular studies of resistant pathogens provide a sensitive and rigorous diagnosis that most of traditional methods cannot offer. They also help to trace the problem and specify the exact cure or drug treatment.

\section{References}

1. Ali BH, Al-Qarawi AA, Bashir AK, Tanira, M0. Phytochemistry, pharmacology and toxicity of Rhazya stricta decne: a review. Phytother Res 2000;14:229-43.

2. Alanis AJ. Resistance to antibiotics: are we in the post-antibiotic era? Arch Med Res 2005;6:797-805.

3. Want SV, Holmes A. Antibiotic resistance and the new antibiotic agents. Clin Intens Care 1999;10:211-8.

4. Ogbolu D0, Daini OA, Ogunledun A, et al. 
High levels of multidrug resistance in clinical isolates of Gram-negative pathogens from Nigeria. Int J Antimicro Ag 2011;37: 62-6.

5. Irving W, Boswell T, Ala'Aldeen D. Medical Microbiology. New York: Taylor \& Francis Group; 2005. pp 244-245.

6. Paterson DL. Resistance in gram-negative bacteria: enterobacteriaceae. Am J Infect Control 2006;34Suppl1:S20-8.

7. Nathisuwan S, Burgess DS, Lewis JS. Extended-spectrum $\beta$-lactamases: epidemiology, detection, and treatment. Pharmacotherapy 2001;21:920-8.

8. Al - Jasser AM. Extended-spectrum $\beta$-lactamases: a global problem. Kuwait Med J 2006;38:171-85.

9. Dias RCS, Borges-Neto AA, Ferraiuoli GID, et al. Prevalence of AmpC and other $\beta$-lactamases in enterobacteria at a large urban university hospital in Brazil. Diagn Microbiol Infec Dis 2006;60:79-87.

10. Keynan Y, Rubinstein E. The changing face of Klebsiella pneumoniae infections in the community. Int $\mathrm{J}$ Antimicrob Agents 2007;30:385-9.

11. Perez F, Endimiani A, Hujer KM, Bonomo RA. The continuing challenge of ESBLs. Curr Opin Pharmacol 2007;7:459-69.

12. Melzer M, Petersen I. Mortality following bacteraemic infection caused by extended spectrum beta-lactamase (ESBL) producing E. coli compared to non-ESBL producing E. coli. J Infect 2007;55:254-9.

13. Mehrgan H, Rahbar M. Prevalence of extended-spectrum $\beta$-lactamase-producing Escherichia coli in a tertiary care hospital in Tehran, Iran. Int $\mathrm{J}$ Ant Agents 2008;31:147-51.

14. Behrooozi A, Rahbar M, Yousefi JV. Frequency of extended spectrum beta-lactamase (ESBLs) producing Escherichia coli and klebseilla pneumonia isolated from urine in an Iranian 1000-bed tertiary care hospital. Afr J Microbiol Res 2010;4:881-4.

15. Rodriguez-Villalobos H, Laurent C, Castany-Prado R, et al. High frequency of CTX-M genes among ESBL-producing Klebsiella pneumoniae in a university hospital in Belgium. Int $\mathbf{J}$ Antimicrob Agents 2007;29:S161.

16. Murki S, Jonnala S, Mohammed F, Reddy A. Restriction of cephalosporins and control of extended spectrum $\beta$-lactamase producing gram negative bacteria in a neonatal intensive care unit. Indian Pediatr 2010;47:785-8.

17. Rangachari RK, Kumar MS, Priyadharsini I. Detection of extended spectrum betalactamase producing gram negative bacilli in urinary isolates. Int $\mathrm{J}$ Biol Med Res 2010;1:130-2.

18. Alfaresi MS, Elkoush AA, Alshehhi HM, Abdulsalam AL. Molecular characterization and epidemiology of extended-spectrum beta-lactamase-producing Escherichia coli and Klebsiella pneumoniae isolates in the United Arab Emirates. Med Princ Pract 2011;20:177-80.

19. Saely S, Kaye KS, Fairfax MR, et al. Investigating the impact of the definition of previous antibiotic exposure related to isolation of extended spectrum $\beta$ Lactamase producing Klebsiella pneumonia. Am J Infect Control Am J Infect Control 2011;39:390-5.

20. Mohanty S, Gaind R, Ranjan R, Deb M. revalence and phenotypic characterisation of carbapenem resistance in Enterobacteriaceae bloodstream isolates in a tertiary care hospital In India. Int J Antimicro Ag 2011;37:273-4

21. Strenger V, Gschliesser T, Grisold A, et al. Orally administered colistin leads to colistin-resistant intestinal flora and fails to prevent faecal colonisation with extendedspectrum lactamase-producing enterobacteria in hospitalised newborns. Int $\mathrm{J}$ Antimicro Ag 2011;37:67-9.

22. Cowan MM. Plant products as antimicrobial agents. Clin Microbiol Rev 1999;12:564-82.

23. Nair R, Chanda SV. Antimicrobial Activities of Some Medicinal Plants of Western Region of India. Turk J Biol 2007;31:231-6.

24. N'guessan JD, Dinzendi MR, Guessennd $\mathrm{N}$, et al. Antibacterial activity of the aqueous extract of Thonningia sanguinea against Extended-Spectrum- $\beta$-Lactamases (ESBL) producing Escherichia coli and Klebsiella pneumoniae strains. Available from: http://www.ajol.info/ index.php/tjpr/ article/view/14659/59733

25. Batanouny KH, Baeshin NA. Studies on the flora of Arabia: I. The Jeddah-Mecca Road, Saudia Arabia. Taeckholmia 1978,9:67-81.

26. Saadabi AMA, Al-Sehemi AG, Al-Zailaie. Iv vitro antimicrobial activity of some Saudi Arabian plants used in folkloric medicine. Int J Bot 2006;2:201-4.

27. Khan S, Khan GM. In vitro antifungal activity of rhazya stricta. Pak J Pharm Sci 2007;20:279-84.

28. Ahmad S, Fatima K, Atiq-ur-Rahman. Antibacterial activity of Pakistani Rhazya stricta. Pakistan J Sci Ind Res 2004;47:2933.

29. Baeshin NA, Sabir JM. Some genetic studies on Aspergillus terreus Thom. Res Sci
KAU, 1987;222:215-24.

30. Baeshin NA, El-Twaty NH, Al-Hebshi AM. Evaluating the Genotoxicity of Rhazya stricta Leaves Extract by the Saccharomyces cerevisiae Auxotrophic Mutants Test. Egypt J Nat Tox 2005;2:88100.

31. Gilani SA, Kikuchi A, Shinwari ZK, et al. Phytochemical, pharmacological and ethnobotanical studies of Rhazya stricta Decne. Phytother Res 2006;21:301-7

32. Abadi FJR, Abdulaziz AM, Hadhoud AA, et al. An epidemiological survey and evaluation of the antimicrobial growth effect of Rhazya stricta (Decne) leaves extract on different genotypes of Neisseria meningitidis. Epidemiol Infect 2007;133:1-7.

33. Baeshin NA, Qari SH, Sabir JS, Alhejin AM. Biochemical and Molecular Evaluation of Genetic Effects of Rhazya stricta (Decne) leaves extract on Aspergillus terreus. Available from: http://ipac.kacst.edu.sa/eDoc/2009/174304 _1.pdf.

34. Tenover FC, Arbeit RD, Goering RV. How to select and interpret molecular strain typing methods for epidemiological studies of bacterial infections: a review for health care epidemiologists. Infect Control Hosp Epidemiol 1997;18:426-39.

35. Healy M, Houng J, Bittner $\mathrm{T}$, et al. Microbial DNA typing by automated repetitive-sequence based PCR. J Clin Microbiol 2005;34:199-207.

36. Criswell D. The "Evolution" of Antibiotic Resistance. Available from: http:/www.icr. org/article/evolution-antibiotic-resistance/

37. Yakubu DY, Abadi FJR, Pennington TH. Moleular typing methods for Neisseria meningitides. J Med Micrbiol 1999;48:1055-64.

38. Nandi S, Ganguly NK, Kumar R, et al. Genotyping of group A streptococcus by various molecular methods. Indian J Med Re. 2008;127:71-7.

39. Ben-Hamouda T, Foulon T, Ben-CheikhMasmoudi A, et al. Molecular epidemiology of an outbreak of multiresistant Klebsiella pneumoniae in a Tunisian neonatal ward. J Med Microbiol 2003;52: 427-33.

40. Fang H, Ataker F, Hedin G, Dornbusch K. Molecular epidemiology of extended-spectrum beta-lactamases among Escherichia coli isolates collected in a Swedish hospital and its associated health care facilities from 2001 to 2006. J Clin Microbiol 2008; 46:707-12.

41. Drabber PD. Introduction to Particle Molecular Biology. Wiley; 1988. pp 13-49. 